\title{
Variability in Total Dust Exposure in a Cement Factory
}

\author{
Hossein KAKOOEI ${ }^{*}$, Ali Akbar KAKOUEI ${ }^{2}$, Abdolhossein POORNAJAF ${ }^{3}$ \\ and Farhad FERASATY ${ }^{3}$ \\ ${ }^{1}$ Department of Occupational Health, School of Public Health, Tehran University of Medical Sciences, Tehran \\ 14155-6446, Iran \\ ${ }^{2}$ Institute of Petroleum Engineering (IPE), School of chemical engineering, University of Tehran, Iran \\ ${ }^{3}$ Department of Occupational Health, Ilam University of Medical Sciences, Iran
}

Received June 9, 2011 and accepted October 31, 2011

Published online in J-STAGE December 6, 2011

\begin{abstract}
Exposure assessment is a main component of epidemiologic studies and variability in exposure. This assessment is considered as a common approach for such phenomenon. A total of 129 dust samples were collected randomly from 197 personnel from a cement factory located in Ilam province, during 2009 in Iran. The between- and within-group components of variability were determined to assess the contrast in exposure level between the Similar Exposure Groups (SEGs) and to calculate the within-worker geometric standard deviation of the theoretical exposure-response slope. Results were analyzing by one-way random effects model. According to the mentioned model, the probability of long-term mean exposure exceeding to the occupational exposure limit (OEL) was assessed for each SEGs. The arithmetic means (AM) of total dust levels ranged from 0.04 to 39.37 $\mathrm{mg} / \mathrm{m}^{3}$. The geometric means (GM) of total dust were higher in the crusher $\left(20.84 \mathrm{mg} / \mathrm{m}^{3}\right)$, packing $\left(17.29 \mathrm{mg} / \mathrm{m}^{3}\right)$, kiln $\left(16.78 \mathrm{mg} / \mathrm{m}^{3}\right)$, cement mill $\left(14.90 \mathrm{mg} / \mathrm{m}^{3}\right)$, and raw mill $\left(10.44 \mathrm{mg} / \mathrm{m}^{3}\right)$. However, the figures for the maintenance and administration parts were $3.77 \mathrm{mg} / \mathrm{m}^{3}$ and $1.01 \mathrm{mg} / \mathrm{m}^{3}$, respectively. The random effects model data demonstrated that the F-value calculated was greater than the critical F-value approximately $59 \%$ of the variability in the exposure was due to differences between groups. Based on these finding, the order of probability of the long-term mean exposure exceeding $(Z)$ to the OEL of $10 \mathrm{mg} / \mathrm{m}^{3}$ for total dust which were in kiln $(100 \%)$, packing $(100 \%)$, cement mill $(90 \%)$, crusher (73\%), raw mill (60\%) administration $(2.3 \%)$ and the maintenance parts $(0 \%)$.
\end{abstract}

Key words: Cement dust, Exposure assessment, Variance components, SEGs

\section{Introduction}

Occupational exposure assessment is an important factor for risk assessment as well as proper sampling strategy. The concentration of an air pollutant is affected by the rates of contaminant generation, task performed, production characteristics and worker activity patterns in the

*To whom correspondence should be addressed. E-mail: hkakooei@sina.tums.ac.ir,kakoeei@gmail.com (C)2012 National Institute of Occupational Safety and Health workplace $^{1-3)}$. In order to avoid the possible bias such as attenuation of the exposure-response slope, a group-based strategy to deal with this problem classifying workers into Similar Exposure Groups (SEGs) ${ }^{4,5)}$. In this approach, the SEGs are constructed based on job, task, processes and environmental agent. Based on this strategy, all individuals are measured within the SEGs and the average exposure is estimated for all members of groups ${ }^{6,4)}$. The sampling and analytical variability in exposure within- and between SEGs can be used to evaluate the probabilities of exceed- 
ance relative to occupational exposure limits (OELs) ${ }^{7,8)}$.

Dust is generated and dispersed into cement factories' air through different production processes ${ }^{9,10)}$. Several clinical and epidemiological studies have shown an increased incidence of impairment of respiratory and a prevalence of respiratory symptoms among cement production workers ${ }^{3,10-12)}$, and potential adverse effects on the respiratory system ${ }^{13-15)}$. Portland cement dust is considered to have potential to induce malignant diseases on the lung such as laryngeal and respiratory cancer ${ }^{16,17)}$. As noted above, occupational exposure to cement dust is likely to vary in different production operations and process ${ }^{9,10,18)}$. Workers who work in the dusty cement production process such as crusher or raw mill have high occupational exposure to total dust $\left(10-230 \mathrm{mg} / \mathrm{m}^{3}\right)$ and respirable dust (2-46 $\left.\mathrm{mg} / \mathrm{m}^{3}\right)^{10,19-21)}$. Kalacic (1973) reported that in the cement production process the aerodynamic diameter range is $0.05-5.0 \mu \mathrm{m}^{222}$.

The aim of this study was to evaluate the levels of personal total dust exposure. The applicable objective was to determine the efficacy of the classification of workers into SEGs for the exposure assessment of large numbers of workers and to assess the probability of overexposure relative to OEL.

\section{Materials and Methods}

\section{Study area and production process}

This study was carried out at a Portland cement factory in Ilam, Iran, from June-October 2009. It is the biggest cement company in the west of the country, currently producing about 600,000 tons of portland cement annually. Around 405 workers are employed. The main process consisted of crushing, raw milling, calcinations in a rotary kiln, cement milling, packing, maintenance and administration. The raw material limestone $(60 \%)$ and red soil (40\%) are crushed before entering the raw mill. The ground materials (fine particles) enter the rotary kiln (with calcining, transition and burning zones) where it is burning at $1,300-1,450{ }^{\circ} \mathrm{C}$ to form clinker. The clinker is mixed with gypsum and ground in the clinker mill into Portland cement. The final product is stored in silos, as bulk or packed.

\section{Study design and subjects}

As mentioned in previous studies ${ }^{7,23,24)}$, the classification of workers into SEGs facilitate the efficient exposure assessment of large numbers of workers. In the factory workers who work into similar job tasks or environmental were assigned into seven SEGs: crusher (group 1), raw mill (group 2), kiln (group 3), cement mill (group 4), packing (group 5), maintenance (group 6) and administration (group 7).

\section{Exposure assessment}

Stratified random sampling method was used for 197 personal total dust samples were allocated into the SEGs. Samples were collected on cellulose acetate filter membranes (Millipore type AA; $0.8 \mu \mathrm{m}$ pore size; $37 \mathrm{~mm}$ diameter) using a closed-face filter holder. Air sampling was performed at a flow rate of $2 \mathrm{l} / \mathrm{min}$ using a personal sampling pump (model 224-PCX R3; SKC-West, Inc., Fullerton, CA, USA), calibrated by a digital automatic calibrator. The sampling of total dust in the breathing zones of the workers was carried out during the 8-h morning shift. Gravimetric analysis using a microbalance with a detection limit of $0.01 \mathrm{mg}$ was employed. The results from the occupational exposure monitoring have compared with OEL of the American Conference of Governmental Industrial Hygienists (ACGIH) which is $10 \mathrm{mg} / \mathrm{m}^{324)}$.

\section{Statistical analysis}

Descriptive statistics were calculated for the AM, GM and GSD of the total dust concentrations using the SPSS software for Windows ver. 13.5 and Microsoft office Excel 2007. A one-way random-effects model also was used to estimate between-group and within-group components of variability $^{1,7,25)}$. In the model, for the $i$ th worker there are $n_{i}$ measurements and the total number of measurements for the SEGs is given by $N=\sum_{i=1}^{k} n i$. Briefly, the random effects model is specified as follows:

$\mathrm{y}_{\mathrm{ij}}=\mu+b_{i}+w_{i j}$

Where $y_{i j}$ is the $\log$-terms $\left(\ln X_{\mathrm{ij}}\right)$ formed exposure of the $i t h$ worker on the $j$ th day; $b_{i}$ is the random effect of the $i$ th worker's mean exposure $\left(\mu_{i}\right) ; \mu$ is the mean exposure of the group; $w_{i j}$ is the random error of the $i$ th worker in the $i$ th group; and $X_{\mathrm{ij}}$ is the exposure concentration for the $i$ th worker on the $j$ th day. The variance of $b_{i}$ is the between worker variability, $\sigma^{2}$, and the random error variance $\left(w_{i j}\right)$ is the within-worker variability, $\sigma^{2}$ w. The two components of variance are independent, and the total variability $\left(\sigma^{2} \mathrm{~T}\right)$ in model (1) is $\sigma^{2}{ }_{\mathrm{B}}+\sigma^{2} \mathrm{w}$. The within-worker variance $\sigma^{2} \mathrm{w}$ is calculated from the analysis of variance (ANOVA) according to the formula is given by

$\sigma^{2}{ }_{\mathrm{w}}=\mathrm{MSW}=\sigma^{2}{ }_{\mathrm{w}}=\mathrm{MSW}=\frac{\sum_{i=1}^{k} \sum_{i=1}^{k}\left(\mathrm{y}_{\mathrm{ij}}-\mathrm{y}_{\mathrm{i}}^{-}\right)^{2}}{(N-k)}$

Where MSW is the mean square within error calculated from the ANOVA table; $y_{i}^{-}$is the mean log-transformed 
Table 1. Total dust exposure $\left(\mathrm{mg} / \mathrm{m}^{3}\right)$ for the workers at a Portland cement factory in Iran categorized into seven SEGs

\begin{tabular}{|c|c|c|c|c|c|c|c|}
\hline & \multirow{2}{*}{$n^{b}$} & \multirow{2}{*}{$\mathrm{n}^{\mathrm{c}}$} & \multicolumn{4}{|c|}{ Dust concentrations $\left(\mathrm{mg} / \mathrm{m}^{3}\right)$} & \multirow{2}{*}{$\begin{array}{l}\text { Dust samples Exceeding } \\
\text { OEL }^{\mathrm{a}} \mathrm{N}(\%)\end{array}$} \\
\hline & & & GM(GSD) & $\mathrm{AM}$ & Median & Range & \\
\hline Crusher & 21 & 30 & $20.84(2.10)$ & 27.49 & 35.03 & $39.37-3.48$ & $22(73 \%)$ \\
\hline Raw mill & 19 & 25 & $10.44(2.20)$ & 14.29 & 17.59 & $33.25-1.59$ & $15(60 \%)$ \\
\hline Kiln & 8 & 10 & $16.78(1.10)$ & 16.86 & 17.23 & $19.45-14.42$ & $10(100 \%)$ \\
\hline Cement mill & 9 & 10 & $14.90(1.60)$ & 16.68 & 18.25 & $19.01-2.37$ & $9(90 \%)$ \\
\hline Packing & 17 & 22 & $17.29(1.05)$ & 17.31 & 17.29 & $19.28-15.22$ & $22(100 \%)$ \\
\hline Maintenance & 10 & 15 & $3.77(1.80)$ & 4.50 & 5.19 & $8.07-1.06$ & $0(0 \%)$ \\
\hline Administration & 45 & 85 & $0.88(4.70)$ & 1.83 & 1.27 & $13.78-0.04$ & $2(2.3 \%)$ \\
\hline
\end{tabular}

AM, arithmetic mean; GM, geometric mean; GSD, geometric standard deviation. ${ }^{a}$ Occupational exposure limit (OEL) for total dust $\left(10 \mathrm{mg} / \mathrm{m}^{3}\right) .{ }^{\mathrm{b}}$ Number of workers for whom measurements were obtained. ${ }^{\mathrm{c}}$ Number of samples.

exposure for the $i$ th worker, i.e., $\mathrm{y}_{\mathrm{i}}^{-}=\left(\sum_{j=1}^{n_{i}} \mathrm{y}_{\mathrm{ij}}\right) / n_{\mathrm{i}}$. The between-worker variance $\sigma^{2}$ В was estimated by

$\sigma^{2}{ }_{\mathrm{B}}=\frac{M S B-M S W}{n_{0}}$

Where MSB is the mean square between error calculated from the ANOVA table, which obtained with the equation by $\mathrm{MSB}=\left(\sum_{i=1}^{k} \mathrm{n}_{\mathrm{i}}\left(\mathrm{y}_{\mathrm{i}}^{-}-\mathrm{y}^{-}\right)^{2}\right) /(k-1)$. Where $\mathrm{y}^{-}$, is the mean of the log-transformed exposure for all workers, i.e., $\mathrm{y}^{-}=\left(\sum_{i=1}^{k} \sum_{i=1}^{n i} y_{i j}\right) / N$. In equation $3, n_{0}$ is equal to: $\left(N-\sum_{i=1}^{k} \frac{n_{i}^{2}}{N}\right) /(/(k-1)$

The F-statistic in this model was estimated by $\mathrm{F}_{k-1, N-k}$ $=\frac{M S B}{M S W}$, where $k-1$ and $N-k$ are the degree of freedom associated with the mean square between worker and the mean square within worker, respectively. When applying one-way random effects model to the data, F-statistic is compared with the critical F-value for a given level of confidence. The GM $(\mu \mathrm{g})$ and GSD $(\sigma \mathrm{g})$ were used to estimate the probability of the long-term mean exposure exceeding (Z) the OEL as described by Rappaport et al. ${ }^{25)}$ :

$P\left(\mathrm{X}_{\mathrm{i}}>\mathrm{OEL}\right)=P\left[Z>\frac{\ln (\mathrm{OEL})-\ln \left(\mu_{\mathrm{g}}\right)}{\ln \left(\sigma_{\mathrm{g}}\right)}\right]$

\section{Results}

The AM, GM and GSD values of total dust in the personal samples are given in Table 1. The crusher, packing, kiln, cement and raw mill had higher GM total dust exposure than the maintenance and administration. The concentrations in $91(49 \%)$ of the 197 personal samples exceeded the recommended OEL based on the ACGIH for nuisance respirable particles, which is $10 \mathrm{mg} / \mathrm{m}^{3}$ of $\operatorname{air}^{24)}$.
Based on our finding, the probability of the long-term mean exposure exceeding to the OEL of $10 \mathrm{mg} / \mathrm{m}^{3}$ for total dust were higher in the kiln $(100 \%)$, packing $(100 \%)$, cement mill (90\%), crusher (73\%), raw mill (60\%) than in the maintenance $(0 \%)$, and administration $(2.3 \%)$ (Table 1). This study confirms that cement factory workers have a higher occupational exposure to total dust in the crusher and packing processes, which is parallel to other findings reported that GM total dust concentrations in the USA cement factory were $2.9 \mathrm{mg} / \mathrm{m}^{3}$, which are lower than in our study ${ }^{18}$, ${ }^{28,29)}$. In general, in this study, the AM and GM of total dust estimated in the factory $\left(14.13\right.$ and $\left.12.12 \mathrm{mg} / \mathrm{m}^{3}\right)$ differ from those reported in some of the previous studies ${ }^{26-28)}$. As noted above, $49 \%$ of the personal measurements exceeded the OEL of $10 \mathrm{mg} / \mathrm{m}^{3}$ for total dust, and all of them sampled in the crusher, packing, cement mill, kiln and raw mill processes. This is consistent with the finding of Rappaport et al., (1995) and Van Tongeren $(2000)^{25,29)}$, in which the overexposure levels $<10 \%$ have indicated as an indicator of acceptable probability of exceedance in the raw mill, maintenance and administration.

Table 2 also shows the results of the random effects model. The $p$-value is less than 0.05 , and $\mathrm{F}$-value calculated is greater than the critical F-value (2.10) for the 0.05 level of significance. Therefore, the between-group variability is significant. Based on the model, the within-group variance $\left(\sigma^{2} \mathrm{w}\right)$ and the between-group variance $\left(\sigma^{2} \mathrm{~B}\right)$ was 1.126 and 1.829 , respectively. The total variability was also $\sigma^{2} \mathrm{~T}=3.095$. Hence, $\frac{\sigma_{B}^{2}}{\sigma_{T}^{2}}$ is equal to 0.590 or roughly 59 $\%$ of the variability in the exposure is due to differences between groups. 
Table 2. One-way ANOVA output table for the total dust concentrations

\begin{tabular}{lccrc}
\hline Source of Variance & Sum of Squares & Degrees of Freedom & Mean Square & F-Value \\
\hline Between groups & $17,740.51$ & 6 & $2,956.75$ & 64.25 \\
Within groups & $8,743.03$ & 190 & 46.01 & \\
Total & $26,483.54$ & 196 & & \\
\hline
\end{tabular}

\section{Discussion}

Variability in total dust exposure in cement factory has rarely been evaluated in Iran. The variability of the total dust exposure were higher among the crusher, packing, kiln and cement mill workers than the other parts of raw mill, maintenance and administration (Table 1). The within- and between-group geometric standard deviation was 2.88 and 3.86, respectively. The cumulative exposure distributions of the seven SEGs' data are shown in Fig. 1. Only workers in the crusher, packing, kiln and cement mill areas (groups 1, 3, 4 and 5), who make crushing or milling, had markedly higher exposure than others (groups 2, 6 and 7). Effects related to between- and within-worker variability have long been recognized in the epidemiologic literature ${ }^{1,5,7)}$. As noted above, in the group-based strategy, statistical analysis involves consideration of between- and within-worker exposure variability ${ }^{30)}$. There is a significance in the variability of the between-groups, because the F-value calculated (64.66) was greater than the critical F-value (2.10). Moreover, the results indicate that the between-group variance (1.829) was relatively greater than within-group variance (1.126) for the SEGs. It is interesting to note that, this variation probably due to the presence of different job and job tasks within the SEGs. Considering that the total variability was 3.095 , our results strongly suggest $\left(\frac{\sigma_{B}^{2}}{\sigma_{T}^{2}}\right)$ that $59 \%$ of the variability in the occupational exposure was largely attributed to the appreciable differences between groups. Congruent with previous studies ${ }^{1,3)}$, our results also confirm that between-group variability was higher than within-group variability. As illustrated in Fig. 1 , the result shows the cumulative percent distribution of all the measurements taken together. This aspect confirms our intuition provoked from the computation of the AM of the log-exposure of the SEGs in Table 1. In general, it is distinct that the total distribution masks the underlying differences between groups within SEGs.

In conclusion, the current study indicated that occupational exposure to cement dust in the factory has considerable variable. Based on the one-way random

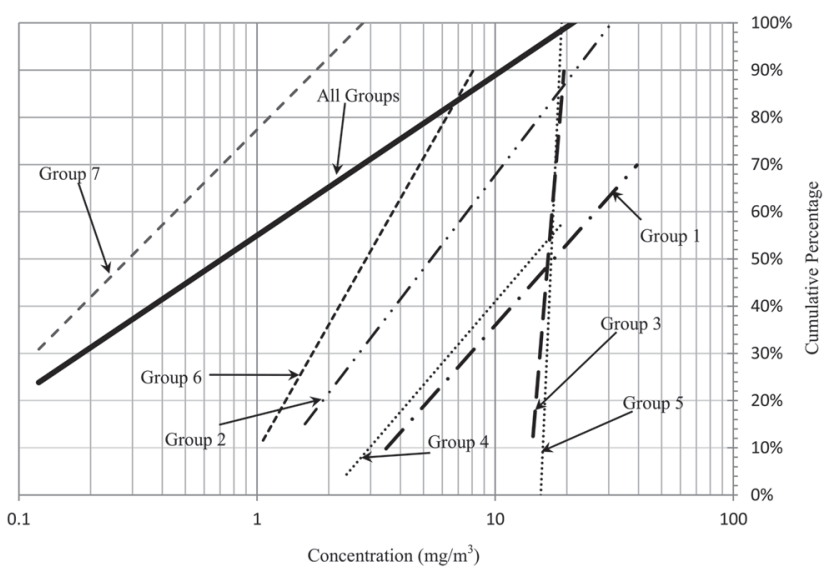

Fig. 1. Cumulative exposure distributions of the seven groups. Groups: 1 (crusher); 2 (Raw mill); 3 (kiln); 4 (Cement mill); 5 (Packing); 6 (Maintenance); 7 (Administration).

model, the long-term mean exposure exceeding to OEL for total dust were higher in the kiln, packing, cement mill, crusher and raw mill processes. Quantitative information about between- and within-group sources of variation in occupational exposure can be used to design useful sampling strategies when risks assessment associated with workplace contaminants.

\section{Acknowledgements}

We thank the manager of Ilam Portland Cement Company, the occupational health director and particularly the workers who had active participation in this study.

\section{References}

1) Kromhout H, Symanski E, Rappaport SM (1993) A comprehensive evaluation of within- and between-worker components of occupational exposure to chemical agents. Ann Occup Hyg 37, 253-70.

2) Kromhout H (2002) Design of measurement strategies for workplace exposure. Occup Environ Med 59, 349-54.

3) Mwaiselage J, Bratveit M, Moen B (2005) Variability in dust exposure in a cement factory in Tanzania. Ann Occup Hyg 49, 511-9. 
4) Loomis D, Kromhout H (2004) Exposure variability: concepts and applications in occupational exposure exposure. Am J Ind Med 45, 113-22.

5) Corn M, Esmen NE (1979) Workplace exposure zone for classification of employee exposure to physical and chemical agents. Am Ind Hyg Assoc J 40, 47-57.

6) Mwaiselage J, Bratveit M, Moen B (2005) Respiratory symptoms and chronic obstructive pulmonary disease among cement factory workers. Scand J Work Environ Health 31, 316-23.

7) Rappaport SM, Kromhout H, Symanski E (1993) Variation of exposure between workers in homogeneous exposure groups. J Am Ind Hyg Assoc 54, 654-62.

8) Mulhausen JR, Damiano J (1998) A strategy for assessing and managing occupational exposures, 2nd Ed., AIHA press, Fairfax.

9) International Labor Organization (1999) Encyclopedia of occupational health and safety.4th Ed., vol.3. ILO, Geneva.

10) Poornajaf A, Kakooei H, Hosseini M, Ferasati F, Kakaei H (2010) The effect of cement dust on the lung function in a cement factory, Iran. Int J Occup Hyg 2, 81-5.

11) Mengesha YA, Bekele A (1997) Effects of acute exposure to different occupational dusts on pulmonary function indices of factory workers in Ethiopia. Africa Newslet Occup Health Safety 7, 8-9.

12) Ali BA, Ballal SG, Albar AA, Ahmed HO (1998) Postshift changes in pulmonary function in a cement factory in Eastern Saudi Arabia. Occup Med 48, 519-22.

13) Oleru G (1984) Pulmonary function and symptoms of Nigerian workers exposed to cement dust. Environ Res 33, 379-89.

14) Yang CY, Huang CC, Chiu HF, LanSJ, Ko CY (1996) Effects of occupational dust exposure on respiratory health of Portland cement workers. J Toxicol Environ Health 49, 581-8.

15) Merenu IA, Mojiminiyi FBO, Njoku CH, IbrahimMTO (2007) The effect of chronic cement dust exposure on lung function of cement factory workers in Sokoto, Nigeria. Africa J of Biomedi Res 10, 139-43.

16) Diertz A, Ramroth H, Urban T (2004) Exposure to cement dust, related occupational groups and laryngeal cancer risk: results of a population-based case- control study. Int J Cancer 108, 907-11.

17) Smailyte G, Kurtinitis J, Andersen A (2004) Mortality and cancer incidence among Lithuanian cement producing workers. Occup Environ Med 61, 529-34.

18) Alvear-Galino MG, Mendez-Ramirez I, Villegas-Rodriguez JA (1999) Risk indicator of dust exposure and health effects in cement plant workers. J Occup Environ Med 41, 654-61.

19) Seifeddin GB, Hafiz OA, Basil AA, Adnan AA, Abdullah YA (2004) Pulmonary effects of occupational exposure to Portland cement: a study from eastern Saudi Arabia. Int J Occup Environ Health 10, 147-9.

20) Mirzaee R, Kebriaei A, Hashemi SR, SadeghiM, Shahrakipour M (2008) Effects of exposure to Portland cement dust on lung function in Portland cement factory workers in Khash, Iran. Iran J Environ Health 5, 201-6.

21) Fairhurst S, Phillips A, Gilles C (1997) Portland cement dust: criteria document for an occupational exposure limit. Health and Safety Executive, London.

22) Kalacic I (1973) Chronic nonspecific lung disease in cement workers. Arch Environ Health 26, 78-83.

23) Nieuwenhuijsen MJ (1997) Exposure assessment in occupational epidemiology: measuring present exposure with an example of a study of occupational asthma. Int Arch Occup Environ Health 70, 295-308.

24) American Conference of Governmental Industrial Hygiene (2008) Threshold limit values for chemical substances and physical agents biological exposure indices. ACGIH, Cincinnati.

25) Rappaport SM, Lyles RH, Kupper LL (1995) An exposure assessment strategy accounting for within-and betweenworker sources of variability. Ann Occup Hyg 39, 469-95.

26) Fell AK, Thomassen TR, Kristenen P (2003) Respiratory symptoms and ventilatory function in workers exposed to Portland cement dust. J Occup Environ Med 45, 1008-14.

27) Abrons HL, Petersen MR, Sanderson WT (1988) Symptoms, ventilation function, and environmental exposures in Portland cement workers. Br J Ind Med 45, 368-75.

28) Noor H, Yap CY, Zolkepli O (2000) Effects of exposure to dust on lung function of cement factory workers. Med $\mathrm{J}$ Malaysia 55, 51-7.

29) Van TongerenM, Kromhout H, Gardiner K (2000) Trends in levels of inhalable dust exposure, exceedance and overexposure in the European carbon black manufacturing industry. Ann Occup Hyg 44, 271-80.

30) Kromhout H, Heederik D (1995) Occupational epidemiology in the rubber industry: implications of exposure variability. Am J Ind Med 27, 171-85. 